\title{
Effects of different inputs of organic matter on the response of plant production to a soil water stress in Sahelian region
}

\author{
Abdoulaye Badiane $\mathrm{e}^{1,2,3^{*}}$, Ndeye Yacine Badiane Ndour $^{2}$, Fatou Guèye ${ }^{2}$, Saliou Faye ${ }^{2}$, \\ Ibrahima Ndoye $^{3}$, Dominique Masse ${ }^{1}$ \\ ${ }^{1}$ Research Center IRD-ISRA-UCAD of Bel-Air Laboratory of Soil Microbial Ecology and Tropical Agrosystems, Dakar, Senegal \\ ${ }^{2}$ Research Centre IRD-ISRA Bel-Air National Laboratory for Research on Crop Production, Dakar, Senegal \\ ${ }^{3}$ Department of Plant Biology, University Cheikh Anta Diop, Dakar, Senegal; \\ *Corresponding Author: badiane abdou@yahoo.fr
}

Received 12 September 2012; revised 15 October 2012; accepted 28 October 2012

\section{ABSTRACT}

The aim was to study the effects of organic management like the application of organic matters on crop production. This research is placed in the context of climate change impact mitigation. A field experiment was conducted during the dry season. Rainfall inputs were simulated by irrigation to study the effects of water stress during the flowering period of a grain on the agronomic and the physiological behavior of the plant. The measurements were made on the volumetric soil moisture, stomatal conductance, and leaf area index (LAI), grain yield, straw and weight of 100 grains. The water use efficiency (WUE) and yield losses were evaluated. The results of the volumetric soil moisture showed that the use of localized input under water stress (STR-T1) recorded the lowest moisture in the surface horizons. Treatment with localized input under water stress with or without fertilization (STR-T1, STR-T1 + N) showed an ability of stomatal regulation compared to the control (STRT0) and the input application by spreading (STRT2). (STR-T1 + N) has initiated an early stomatal closure of the plant because of the effect of nitrogen. However, despite a more pronounced water stress with stomatal closure, the LAI and the grain yield were greater with (STR-T1) and $($ STR-T1 + N). The results showed that the inputs of localized organic fertilization with or without nitrogen grain yields were the highest regardless of the hydric regime applied. However the losses of grain yield were higher in treatments with organic inputs in spreading and localized under water stress. The WUE by the crop was reduced compared to the control with organic inputs under STR. In this study we show that the use of organic matter increases de farmers risk and this notion of risk is high and it is necessary to consider this risk in the proposals of technical innovations.

Keywords: Organic Matter; Water Stress; Volumetric Soil Moisture; Stomatal Conductance; Leaf Area Index

\section{INTRODUCTION}

The objective of this study was to determine the effect of soil amendment by organic matter on plant production under soil water stress. The climate change scenarios forecast a recurrence of the phenomena of extreme event as dry period during the rainy season [1]. These rainfall disorders could cause significant decreases in yields of rainfed agriculture. Agricultural productions and access to food will therefore be severely affected in many sahelian countries, with serious consequences for food security [1]. In this context it is crucial to better understand the functioning of cultivated soils in situations of soil water stress. [2] also showed that the effect of rainy deficit on corn results in a reduction in biomass yield and harvest index. Studies [2,3] have shown that the period around flowering is the step where corn production is more sensitive to water deficit. Reference [4] revealed that the harvest index was affected by soil water stress when the stress was imposed during flowering period. Among the agricultural practices, the management of soil fertility through the use of mineral or organic fertilizer is essential to ensure sustainable agricultural production (Sun et al., 2003) [5]. It is shown that soil organic matter can modified the soil water dynamic, the plant root system and ultimately the performance of cereal crops. Ref 
erence [6] showed that when rainfall is low or deficient, the positive effect of fertilization on production decreases. Soils fertilized by organic manure dried faster than soils without manure fertilization [7]. It is widely known that organic amendments such as plant residues, manure or compost have benefits for soils physical [8] and chemical properties [9]. Few experimental studies have been conducted in arid zone of West Africa to assess the role of organic inputs in agricultural soils under water deficit. Therefore, an experiment was set up during the dry season with a strict control by irrigation of water quantities provided on a corn crop. The hypothesis tested is that the addition of organic matter, especially its application mode, localized or spread allow a culture and soil properties to cope with soil water stress. For this, an artificial water stress was applied at the flowering period of a corn crop fertilized with localized versus spread organic inputs. The experiment was conducted during the dry season for a better control of experimental water supply. The results presented were about the effect of the different tested (rainy deficit and organic matter input) factors on the soil water dynamic, crops ecophysiological parameters and yield of corn.

\section{MATERIALS AND METHODS}

\subsection{Study Site}

The study site is located in the National Center for Agricultural Research Bambey (latitude $16^{\circ} 28^{\prime} \mathrm{N}$, longitude $14^{\circ} 42^{\prime} \mathrm{O}$ ) in Senegal. The climate is Sahelian, with a monomodal rainy season marked by a long dry season (November-May) and a short rainy season (June-October). The average annual rainfall was $499 \mathrm{~mm}$ from 1989 to 2009. The soils are of type Arenosols according to the classification [10]. The soil was a ferruginous soil type as described by reference according to the French taxonomy, established on aeolian quaternary sand cover [7]. The granulometric characteristics of the soil are identical to those described in reference [7] with a loamy sand texture, poor in organic matter. The homogeneous topography conferred a very low variability of soil physico- chemical characteristics. In the study site, initial total carbon in the soil $(0-10 \mathrm{~cm} \mathrm{depth})$ was $24.6 \mathrm{~g} \cdot \mathrm{kg}^{-1}$, and total nitrogen was $2.2 \mathrm{~g} \cdot \mathrm{kg}^{-1}$.

\subsection{Experimental Device}

The device was set up in the dry season (March-June 2010) with an irrigation system. Three factors were tested. The first factor represents two hydric regimes. The first hydric regime was based on twice weekly irrigation to reach a total water equivalent to the maximum evapotranspiration (ETM). The second treatment (STR) was the same as ETM until the 60th day after sowing (DAS), then irrigation was stopped until the 74th (DAS). Water applications were performed with an overhead irrigation system with tilting ramps. The total quantities of water provided throughout the crop cycle are $385 \mathrm{~mm}$ for the regime called stress (STR) and $445 \mathrm{~mm}$ for the regime called ETM. The second factor is about the different modes of application of organic matter inputs: without addition of organic matter (T0), with localized supplies of manure in each seedling planting hole of the experimental unit (T1), with an input of manure spread over the entire surface of the experimental unit (T2). The same amount of organic input was applied by experimental unit. The third factor was whether to add mineral nitrogen $(+\mathrm{N})(-\mathrm{N})$ in the form of urea with a concentration level of $200 \mathrm{~kg} \cdot \mathrm{ha}^{-1}$. The manure was collected in cattle parks. The application rate was $5 \mathrm{Mg} \cdot \mathrm{ha}^{-1}$ of dry matter. In soudano-sahelian zone, mineral nitrogen associated with organic matter could be used in conventional practices. We decided to test the organic matter addition with or without mineral nitrogen to refer to the farmer fields. The objective was also to compare the results to a positive control in opposition to the control with no organic matter or mineral nitrogen addition. The experimental design is a split plot with four blocks as repetition. Each block is thus divided into two large parcels of six elementary plots with an area of $24 \mathrm{~m}^{2}$. On large plots were applied water factor (STR and ETM). The large plot was divided in six plots and the 12 treatments from the crossing of two factors, organic matter inputs and urea application, were randomly assigned to. The plots were planted with the local variety Suwan of corn. Sowing was made in planting holes with a distance of $0.25 \mathrm{~cm}$ intra row and inter-line of $0.80 \mathrm{~cm}$. Cultural practices consisted of two weedings in the 12th and 34th DAS. The crop cycle lasted 90 days.

\subsection{Measurements and Observations}

Profiles of soil moisture have been made on treatment not associated with nitrogen fertilization. Observations were made on the plant in the beginning, during and the day before the end of the soil water stress. The yield of the crop was estimated at the end of the crop cycle.

\subsection{Volumetric Soil Moisture}

The soil moisture was determined by the gravimetric method. Using an auger, soil samples were collected from a depth until the wetting front from $0 \mathrm{~cm}$ to $250 \mathrm{~cm}$ at the beginning (60th DAS), at the middle (67th DAS) and at the end of the water stress period (73th DAS). The samples collected were weighed before (Psf) and after oven drying $\left(105^{\circ} \mathrm{C}\right.$ for 72 hours). The moisture content $(\mathrm{Hp} \%)$ is calculated from the following equation:

$$
\mathrm{Hp}(\%)=(\text { Psf }- \text { Pss } / \text { Pss } \times 100) \text {. }
$$


The soil bulk density (SBD) was measured by sample a volume of soil that was weighed after oven drying $\left(105^{\circ} \mathrm{C}\right)$. The volumetric soil moisture $\left(\mathrm{Hv}\right.$ in $\left.\mathrm{cm}^{3} / \mathrm{cm}^{3}\right)$ was calculated from the following equation.

$$
\mathrm{Hv}=\mathrm{Hp} * \mathrm{SBD} \text {. }
$$

\subsection{Ecophysiological Parameter}

Stomatal conductance and leaf area index were measured to assess the effects of water stress on plant physiological parameters.

\subsection{Stomatal Conductance}

Daily stomatal resistance (Rs) was measured at 67 th day after sowing using the vapor diffusion porometer balance (model LI 1600, LI-COR, USA). This resistance was then converted to stomatal conductance

$$
\left(\mathrm{Gs}=\mathrm{mmol} \mathrm{m} \mathrm{m}^{-2} \cdot \mathrm{s}^{-1}\right): \mathrm{Rs}=1 / \mathrm{Gs} \text {. }
$$

The measurements were made on the third leaf from the first leaf of the top and on two different plants of an elementary plot.

\subsection{Leaf Area Index}

The leaf area index (LAI) was measured from the 60th to 75th days after sowing using the analyzer LICOR LAI-2000 (Li-cor ${ }^{\circledR}$, Inc., Lincoln, Nebraska 68504, United States). Five measurements were made. The first was made above the canopy and the other four under the canopy along the diagonal of the plot. The calculations were performed automatically by the device simultaneously with the measurements.

\subsection{Plant Production Assessment}

The yield of grain and straw of corn by the weight of dry matter (etuve drying at $65^{\circ} \mathrm{C}$ for $72 \mathrm{hrs}$ ) and the weight of 100 grains was determined from the evaluation of the quantity of grain obtained on an area of $11.4 \mathrm{~m}^{2}$ plot corresponding to the useful portion of the experimental unit. The water use efficiency by the crop was determined by the ratio of grain yield of each treatment on the total amount of irrigation water applied as described by [11]. The percentage of yield loss relatively to the water stress effect was calculated using the following formula:

$$
\text { (Yield ETM - Yield STR)/Yield ETM*100. }
$$

\subsection{Statistical Analysis}

The statistical analysis was performed with XLSTAT software. The analysis of variance (ANOVA) and Fisher's averages test at 5\% were used to test the effect of different factors on the measured parameters and to classify levels of treatment.

\section{RESULTS}

\subsection{Volumetric Soil Moisture}

Figures 1(a)-(c) shows the water profiles measured in the different before the stress period (60th DAS), during the stress period (67th DAS) and on the day before of the removal of the water stress (73th DAS) in the treatment STR and also ETM. A measure was performed before the start of irrigation. The soil water content (SWC) profile

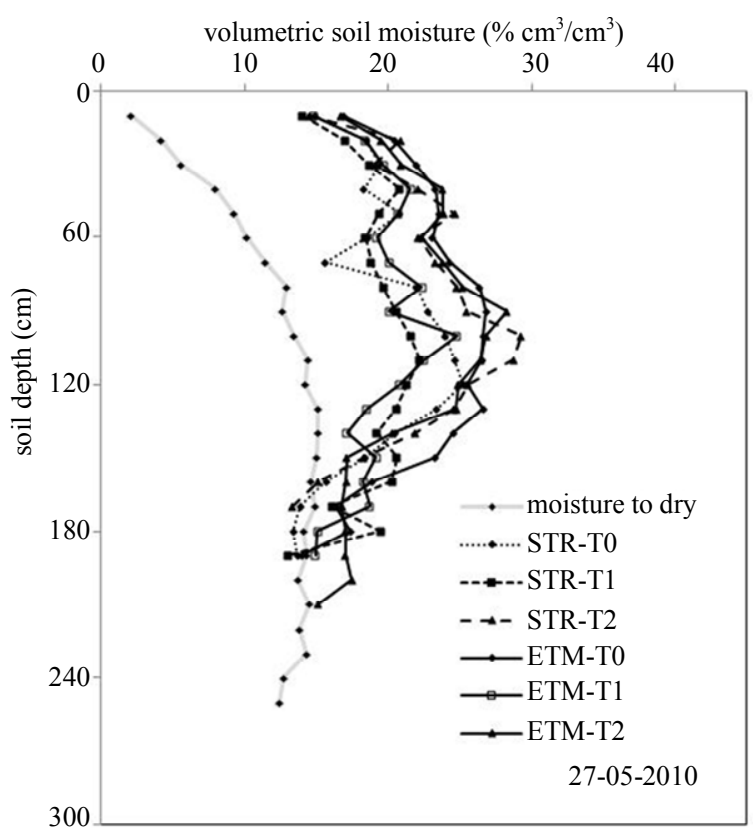

(a) $60^{\text {ème }}$ DAS

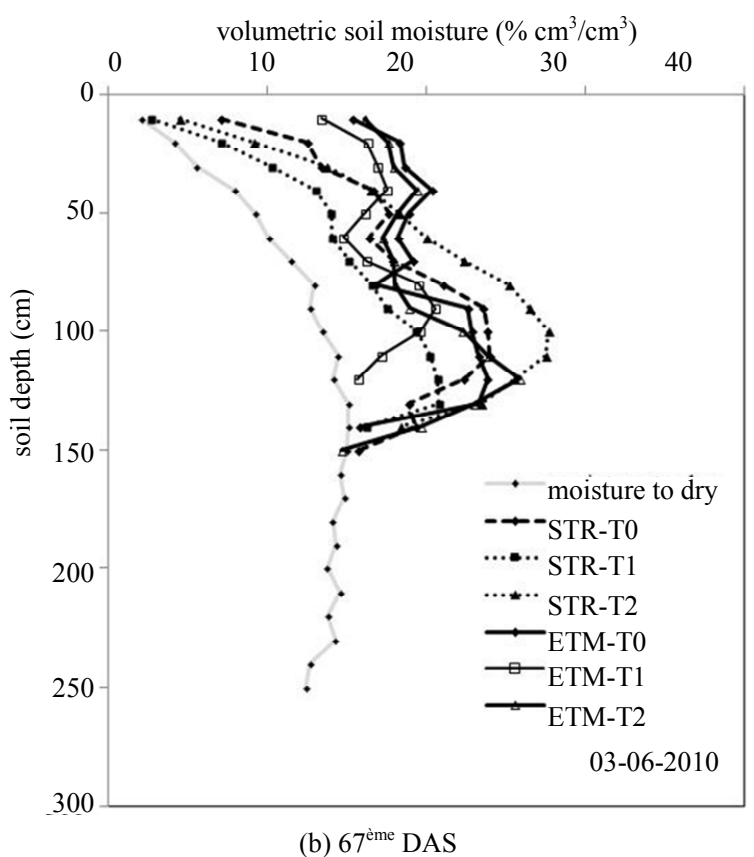




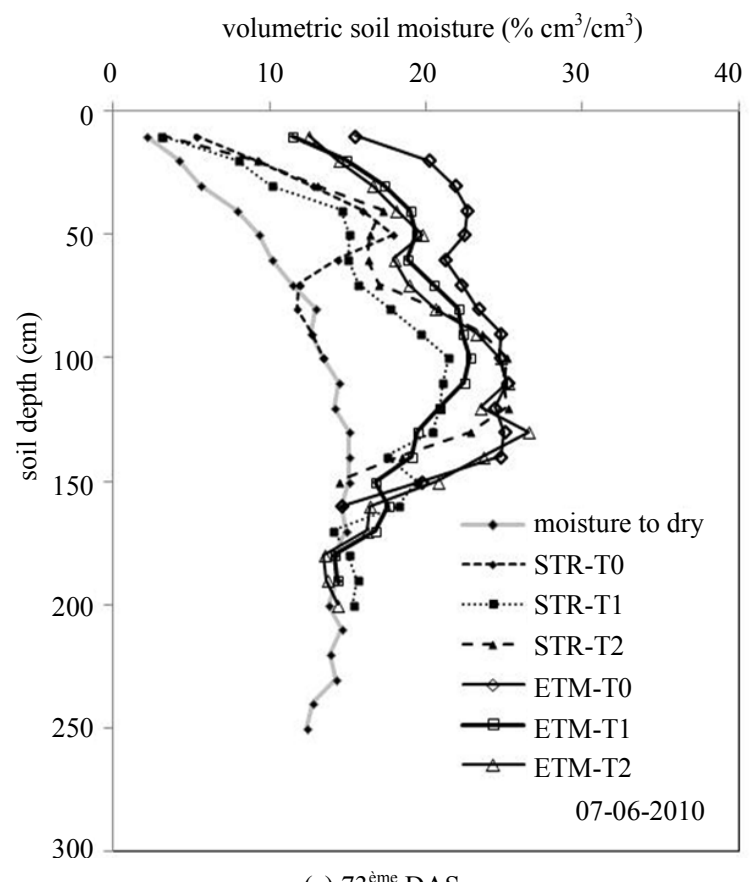

(c) $73^{\text {ème }}$ DAS

Figure 1. Volumetric soil moisture $(\mathrm{V} / \mathrm{V})$ at different stages after sowing measured on field experience. The treatment with the application of water stress (STR) was compared to a treatment with the application of water equivalent to the maximum evapotranspiration (ETM). In both cases, the localized input (T1) and the spreading of organic matter (T2) were compared to the control treatment (T0) without addition of organic matter. The dashed lines are the treatments under water stress and solid lines are the maximum evapotranspiration treatments. showed that soil moisture increased steadily to a depth of $100 \mathrm{~cm}$. Beyond that depth, the soil water content remained substantially constant until the maximum depth measured. Variations in soil moisture measured at three periods of the crop cycle are observed up to $150 \mathrm{~cm}$ deep. Beyond that the soil water content was not modified. At 60th DAS, before the beginning of the water stress, the plots of the two treatments ETM and STR showed little difference soil water profiles. At the 67th DAS, the soil water content on the treatment STR regularly decreased between 0 to $50 \mathrm{~cm}$ depth. Beyond that depth, both treatments showed slightly different of soil moisture until the $150 \mathrm{~cm}$ depth. At 73 DAS, the soil water content along all the profile did not differ.

In the ETM plots, organic matter was added (T1 and T2 treatments); soil water content was lower compared to those measured in plots without organic matter inputs (T0). Soil water contents measured on the plots STR during the period of stress were lower in plots with localized manure input (STRT1) than those measured on plots where manure was spread (STRT2) and on the control (STRT0) (Figures 1(b) and (c)).

\subsection{Stomatal Conductance}

Stomatal conductance was reduced for all plants located in the STR plots comparatively to plants on ETM plots (Figures 2(a) and (b)). The treatment (STR-T1) showed a stomatal closure at the mid-day, only in the case of the localized organic matter input treatment (STR-T1). The mechanism of stomatal regulation for the

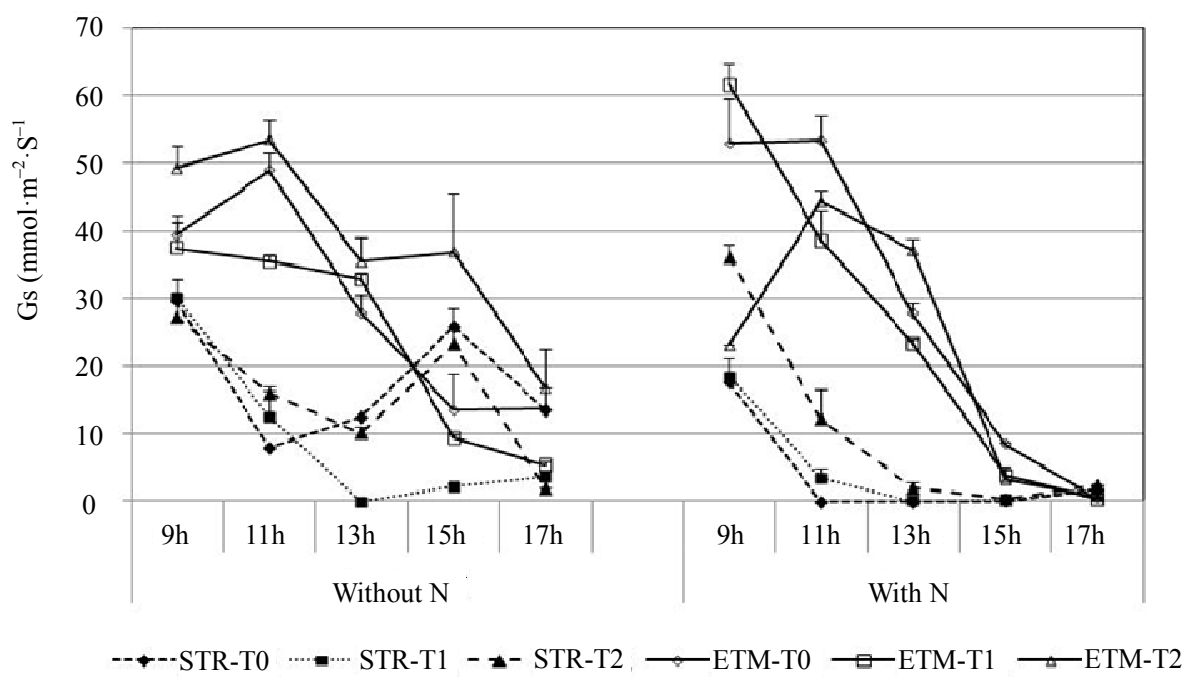

(a)

(b)

Figure 2. Daily change of stomatal conductance of corn. Practices of organic and mineral inputs and hydric regime were compared. The treatment with water stress (STR) was compared to the treatment with maximum evapotranspiration (ETM). In both cases, the localized input (T1) and spreading of organic matter (T2) were compared to the control treatment (T0) without addition of organic matter. The dashed lines are the treatments under water stress and solid lines are the treatments under maximum evapotranspiration. Vertical bars are the standard error. 
treatment (STR-T1) moved faster than those from plots T2 and T0 plots of the STR treatments.

\subsection{Leaf Area Index}

The lowest plants leaf area index was measured on STR plots (Figures 3(a) and (b)). However, the localized organic input treatment associated or not with nitrogen fertilization (STR-T1) recorded higher leaf area index than those measured on spread organic inputs treatments
(STR-T2) or without organic matter addition treatment (STR-T0).

\subsection{Corn Yield}

The water stress application resulted in significantly lower grain yields (Table 1) compared to those measured ETM plots. The organic matter amendment enhanced the effect of water stress on grain yield. However, the nitrogen addition reduced the impact of water stress on yield

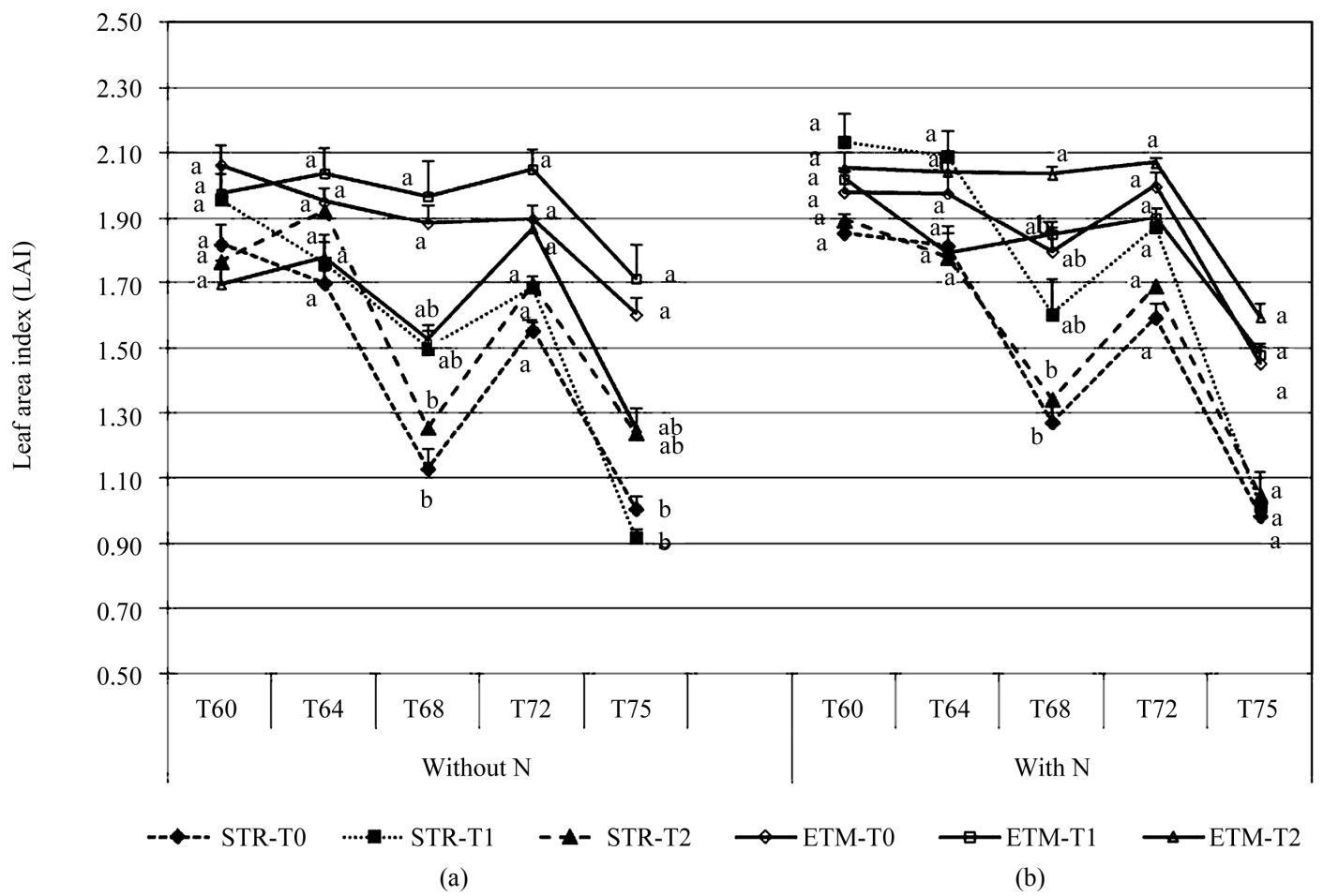

Figure 3. Change in leaf area index of maize based on the time (from 60th to 75th days after sowing). Treatments under water stress (STR) with organic and mineral inputs were compared to the same treatments with maximum evapotranspiration (ETM). In both cases, the localized input (T1) and spreading of organic matter (T2) were compared to the control (T0) without addition of organic matter. The dashed lines are the treatments under water stress and solid lines are the treatments under maximum evapotranspiration. Vertical bars are the standard error.

Table 1. Effects of organic inputs application methods. Localized input $=\mathrm{T} 1$, spreading input $=\mathrm{T} 2$, control $=\mathrm{T} 0)$, the nitrogen $(+\mathrm{N})$ and hydric regime (water stress $=$ STR, maximum evapotranspiration $=$ ETM) on corn grain yield and water use efficiency by the plant. For the two consecutive columns, data with the same letter are not significantly different $(\mathrm{P}<0.05)$.

\begin{tabular}{ccccc}
\hline & \multicolumn{2}{c}{ Grain Yield $\left(\mathrm{kg} \cdot \mathrm{ha}^{-1}\right)$} & \multicolumn{2}{c}{ Water Use Efficiency $\left(\mathrm{kg} \cdot \mathrm{m}^{-3}\right)$} \\
\cline { 2 - 4 } Treatments & STR & ETM & STR & ETM \\
\hline T0 & $256.75 \pm 28.45 \mathrm{c}$ & $358.25 \pm 138.49 \mathrm{abc}$ & $0.067 \mathrm{~b}$ & $0.08 \mathrm{ab}$ \\
$\mathrm{T} 1$ & $377.50 \pm 30.77 \mathrm{abc}$ & $936.00 \pm 74.45 \mathrm{ab}$ & $0.10 \mathrm{ab}$ & $0.21 \mathrm{a}$ \\
T2 & $309.50 \pm 40.37 \mathrm{c}$ & $955.25 \pm 376.41 \mathrm{a}$ & $0.08 \mathrm{ab}$ & $0.21 \mathrm{a}$ \\
T0 + N & $135.75 \pm 9.66 \mathrm{c}$ & $364.50 \pm 33.12 \mathrm{abc}$ & $0.04 \mathrm{ab}$ & $0.08 \mathrm{ab}$ \\
T1 + N & $521.0 \pm 72.37 \mathrm{abc}$ & $456.00 \pm 46.53 \mathrm{abc}$ & $0.14 \mathrm{ab}$ & $0.10 \mathrm{ab}$ \\
T2 + N & $338.50 \pm 51.91 \mathrm{bc}$ & $333.00 \pm 46.86 \mathrm{c}$ & $0.088 \mathrm{ab}$ & $0.075 \mathrm{ab}$ \\
\hline
\end{tabular}


for treatments associated with organic fertilization. The results showed that in the STR plots, the plots with a localized organic fertilization input with or without nitrogen (T1) had higher grain yields compared to treatments without organic matter addition: the yield losses due to water stress would be $67 \%$ for the treatment spreading (T2), (59\%) for localized input (T1) and 28\% for the control (T0). The results obtained for straw yield showed no significant difference between treatments (Table 2). The weight of 100 grains was significantly higher in ETM plots compared to STR plots. However the localized organic matter inputs and nitrogen addition had reduced the depressive effect of water stress on the weight of 100 grains. Thus, the difference between the weight of 100 grains $(\mathrm{T} 1+\mathrm{N})$ between ETM and STR plots was not significant. The water use efficiency (WUE) expressed according to the ratio of grain yield on the quantity of water supplied was significantly higher for the plots with added organic matter (T1 and T2) in ETM treatment compared to those that were on STR plot (Table 1). There were no significant effects of the supply practice of organic matter amendment or nitrogen fertilization on the WUE.

\section{DISCUSSION}

\subsection{Effects of Organic Matter Input Management on the Soil Water Profile}

The soil water content measured by the volumetric soil moisture decrease due to the lack of rain during the maize flowering period was greater where organic matter were locally supplied to the plant compared to the one observed on plots without any organic or with addition of organic matter spread on the surface of the plot. This dryness relatively high may be caused by an over-intake of water by the plant which in this case, localized organic amendment, had a stronger biomass and therefore an increased need for water, that was confirmed by the highest LAI measured in the case of this treatment.

\subsection{Effects of Organic Matter Management on the Plant Responses to Water Stress}

The water availability plays a key role in opening and closing of stomata. In the case of the localized organic inputs, the plant response under water depletion by a resistance to stomatal conductance indicating a faster stomatal closure at the mid day comparatively to that was observed in the other treatment. This stomatal closure reduce water loss by transpiration and indicates a good physiological capacity of stomatal regulation. These results corroborate those reported in the literature. Indeed, [12] showed that under conditions of water stress the stomata close in response to a loss of cell turgor pressure. However, this was not the case for plants on plots with spread organic matter input. An input of mineral $\mathrm{N}$ also induces an early stomatal closure from $11 \mathrm{~h}$ am continuing until the end of the day. This stomatal closure, whether in the case of localized input or the input of mineral nitrogen, indicates that the plants were in a situation of lack of water faster than plants from other treatments. Presumably, these plots had a higher biomass at the beginning of the period of stress. This biomass induced water needs more important and that explain the plant response at the time of stress. The results obtained for the (LAI) show indeed that it is higher for localized input compared to the controls and spread input application. The leaf area index is a good indicator of water stress for plant during flowering by comparing stressed and unstressed situations. The leaf expansion is one of the first growth process of the plant to be affected by water stress $[3,4,13]$. Finally, grain yields were not significant between the different management of input of organic matter under the effect of water regime. The negative effect of water stress was much stronger than the plant had a higher biomass at the time of application of the stress.

\section{CONCLUSION}

The addition of localized organic matter created on the

Table 2. Effects of organic inputs application methods (localized inputs $=\mathrm{T} 1$, spreading of input $=\mathrm{T} 2$, control $=\mathrm{T} 0$ ), the nitrogen $(+\mathrm{N})$ and hydric regime (water stress $=$ STR, maximum evapotranspiration $=$ ETM) on the straw yield and the weight of 100 grains. For the two consecutive columns, data with the same letter are not significantly different $(\mathrm{P}<0.05)$.

\begin{tabular}{|c|c|c|c|c|}
\hline \multirow[b]{2}{*}{ Treatments } & \multicolumn{2}{|c|}{ Straw yield $\left(\mathrm{kg} \cdot \mathrm{ha}^{-1}\right)$} & \multicolumn{2}{|c|}{ Weight of 100 grains (g) } \\
\hline & STR & ETM & STR & ETM \\
\hline T0 & $3430.5 \pm 79.71 \mathrm{~ns}$ & $3053.25 \pm 481.68 \mathrm{~ns}$ & $6.89 \pm 0.07 \mathrm{~h}$ & $10.43 \pm 0.06 \mathrm{de}$ \\
\hline $\mathrm{T} 1$ & $4339 \pm 150.73 \mathrm{~ns}$ & $5477 \pm 200.77 \mathrm{~ns}$ & $9.52 \pm 0.06$ ef & $16.48 \pm 0.10 \mathrm{a}$ \\
\hline $\mathrm{T} 2$ & $3189,75 \pm 159.31 \mathrm{~ns}$ & $4386.25 \pm 128.98 \mathrm{~ns}$ & $8.075 \pm 0.01 \mathrm{~g}$ & $14.83 \pm 0.24 \mathrm{~b}$ \\
\hline $\mathrm{T} 0+\mathrm{N}$ & $4062,25 \pm 568.10 \mathrm{~ns}$ & $4026 \pm 256.09 \mathrm{~ns}$ & $4.825 \pm 0.13 \mathrm{i}$ & $8.82 \pm 0.19 \mathrm{fg}$ \\
\hline $\mathrm{T} 1+\mathrm{N}$ & $4735 \pm 367.13 \mathrm{~ns}$ & $4673 \pm 215.63 \mathrm{~ns}$ & $11.52 \pm 0.07 \mathrm{~cd}$ & $12,38 \pm 0.08 \mathrm{c}$ \\
\hline $\mathrm{T} 2+\mathrm{N}$ & $3559 \pm 364.50 \mathrm{~ns}$ & $4710 \pm 162.93 \mathrm{~ns}$ & $8.91 \pm 0.07 \mathrm{fg}$ & $10.17 \pm 0.06 \mathrm{e}$ \\
\hline
\end{tabular}


soil islands of fertility that allow the plant to draw nutri ents necessary for growth and productivity. However the effect of water stress has been severe for the plant in this treatment compared to the treatment associated with spreading input and the control. It therefore appears that the gain of a practice of increasing intake of organic or mineral can be quickly reduced by a drought that would take place during flowering. This study shows that the notion of risk is high and it is necessary to consider this risk in the proposals of technical innovations. To limit this risk the effect of late water stress in plots with high inputs of organic fertilizers, will require a better control of rain water by promoting the concentration of water resources for the plant just like for the concentration of the nutrient resource.

\section{ACKNOWLEDGEMENTS}

We thank the AIRD (Inter-establishment Agency of Research for Development), which funded the study through the project of interdisciplinary research and participatory interactions between climate and societies in West Africa (FSP-RIPIECSA) of the French Ministry of Foreign Affairs. We also thank the project INTAC (integrating adaptation to climate change in sustainable development in Senegal) of Ministry of Environment of Senegal supported by the Japanese Cooperation and the UNDP which offered me a scholarship .To all those who participated in this work, the institutions IRD (LEMSAT), ISRA (CERAAS teams) who welcomed me.

\section{REFERENCES}

[1] IPCC (2007) Climate change. Contribution of Working Groups I, II and III to the Fourth Assessment Report of the Intergovernmental Panel on Climate Change. IPCC, Geneva, 103 pages.

[2] Farré, I. and Faci, J.M. (2009) Deficit irrigation in maize for reducing agricultural water use in a Mediterranean environment. Agricultural Water Management, 96, 383-394. doi:10.1016/j.agwat.2008.07.002

[3] Pandey, R.K., Maranville, J.W. and Amdou, A. (2000) Deficit irrigation and nitrogen effect on maize in sahelian environment. I. Grain yield and yield components. Agricultural Water Management, 46, 1-13.
doi:10.1016/S0378-3774(00)00073-1

[4] Traoré, S.B., Carlson, R.E., Pilcher, C.D. and Rice, M.E. (2000) Bt and Non-Bt maize growth and development as affected by temperature and drought stress. Soil Sciences Society of America Journal, 92, 1027-1035.

[5] Sun, B., Zhou., S.L. and Zhao., Q.G. (2003) Evaluation of spatial and temporal changes of soil quality based on geostatistical analysis in the hill region of subtropical China. Geoderma, 115, 85-99. doi:10.1016/S0016-7061(03)00078-8

[6] Affholder, F. (1994) Variabilité des rendements du mil pluvial en milieu paysan Sénégalais: Influence de l'alimentation hydrique, de la gestion de la fertlité et du contrôle de l'enherbement. In: Reyniers, F.N. and Netoyo, L. Eds., Bilan Hydrique et Sécheresse en Afrique Tropicale, J. Libbey Eurotext, Paris, 191-203.

[7] Affholder, F. (1995) Effect of organic matter input on the water balance and yield of millet under tropical dryland condition. Field Crops Research, 41, 109-121. doi:10.1016/0378-4290(94)00115-S

[8] Roberson, E.B., Sarig, S., Sheunan, C. and Firestone, M.K. (1995) Nutritional management of microbial polysaccharide production and aggregation in an agricultural soil. Soil Sciences Society of America Journal, 59, 1587-1594. doi:10.2136/sssaj1995.03615995005900060012x

[9] Wander, M.M., Traina, S.J., Stinner, B.R. and Peters, S.E. (1994) Organic and conventional management effects on biologically active soil organic matter pools. Soil Sciences Society of America Journal, 58, 1130-1139. doi:10.2136/sssaj1994.03615995005800040018x

[10] FAO (2006) World reference base for soil resources. A framework for International classification, correlation and communication. Food and Agriculture Organization, Rome, Italy, 103 pages.

[11] Di Paolo, E. and Rinaldi, M. (2008) Yield response of corn to irrigation and nitrogen fertilization in a Mediterranean environment. Field Crops Research, 105, 202-210. doi:10.1016/j.fcr.2007.10.004

[12] Kramer, P.J. (1983) Water Relations of Plants. Academic Press, New York, 404-406.

[13] Çakir, R. (2004) Effect of water stress at different development stages on vegetation and reproductive growth of corn. Field Crops Research, 89, 1-6. doi:10.1016/j.fcr.2004.01.005 